\title{
Application of Yospan as a Programmatic Method for Spatial Experience and Flexibility in the Central Marketplace of Manokwari
}

\author{
Asterica D. A. Darmawanto, and Purwanita Setijanti \\ Department of Architecture, FTSP, Institut Teknologi Sepuluh Nopember (ITS) \\ Jl. Arief Rahman Hakim, Surabaya 60111 \\ E-mail: psetijanti@arch.its.ac.id
}

\begin{abstract}
As a coastal city, Manokwari's coastline is where the central development grows, one of which is the Sanggeng Marketplace. This central market area is a vital system in the city. Yet, it lacks the development required to accommodate future growth and risks. The issue at hand discusses the marketplace's position as a commercial and recreational space and how both can be integrated into a space that caters to the bright, multicultural citizens of the city of Manokwari.

The design proposed in this final project accommodates the merging of both commercial, recreational, and social spaces in a single marketplace through spatial flexibility and the programming of spatial experiences. By designing a marketplace that not only delivers flexible spatial functions but also reflects the vibrancy and provides a spatial experience, the Sanggeng Market can exist as a central marketplace that can significantly further benefit the city, both economically and socially.
\end{abstract}

Keyword-Flexibility, Marketplace, Programming Public Space.

\section{INTRODUCTION}

$\mathrm{T}$ he coastline of Manokwari is the central development zone where most commercial activities take place. A strong economic system is important for a city to grow, yet this area have not experienced major change to accommodate future growth, especially in the central market area (the Sanggeng Market).

The existing Sanggeng Market is a combination of a traditional open market and a "modern" wholesale market in a multi-story building. It suffers from poorly managed facilities, weak infrastructure, lack of proper building systems. Yet, it possesses the advantages that makes it into a central marketplace of the city.

The issue at hand discusses the marketplace's position as a commercial and recreational space and how both can be integrated into a space that caters to the bright, multicultural citizens of the city of Manokwari. The fundamental criteria for the central marketplace is to provide integrated spaces that functions as commercial, recreational, and social hub. The intended design must also express imagery or spatial experiences that is of value to the cultural landscape of Manokwari. Therefore, the object intended requires an approach that focuses on spatial flexibility and programming.

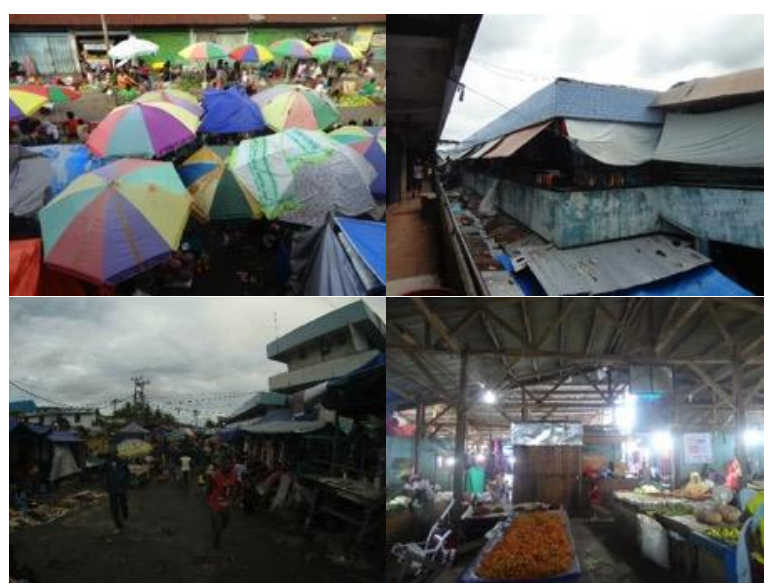

Figure 1. Existing condition of the Sanggeng Market

\section{DESIGN EXPLORATION AND DESIGN PROCESS}

\section{A. Design Approach}

The approaches applied to the design first consists of a flexible space design which utilizes the programming method as defined by Bernard Tschumi [1]. It is the method of understanding each program and its activities and determining the programmatic relationship between each to create a flexible space. The second approach is an approach to determine the spatial experience and spatial flow of the site through the expression of local culture by using one of Anthony Antoniades's transformational strategy [2]. This approach is the act of borrowing formal departures from other artefacts/subject, learning their two-dimensional or three-dimensional properties while constantly probing interpretations with regards to their applicability and validity.

The site is approximately $2.86 \mathrm{Ha}$ and located in the Sanggeng Bay area. It borders on mainly residential areas to the north and south, a main road and commercial zones to the west, and the bay area to the east.

\section{B. Design Method}

There are two methods applied in the process of this design. The first method is to achieve program and spatial organization and the second is to create spatial experiences and flow.

\section{Program and Spatial Organization}

The programs within the market are first investigated to find the various relationships between them in order to create an overlap between them. This overlap will act as a 
base for spatial organization, experience, zoning, and massing in the future.

This overlap is achieved from studying a matrix of programmatic relationships [3] to determine whether the desirable or non-desirable relationships. Further observations come from studying each of its operational hours and the connecting relationship between each of them.

\section{Spatial Experiences \& Flow}

An aspect to remember is that the object is always affected by its context. In this case, it is the cultural context. The people of Manokwari is characterized by their youthful festivities that are ingrained from local cultures. Music and dance play a large part in influencing the contemporary scene; one of which is the Yospan dance. Yospan is a contemporary dance in Papua; it is a hybrid of the Yosim and Pancar dance [4] that expresses the youthful spirit of Papua through the simple yet upbeat nature of both its music and movements.

The borrowing approach essentially uses interpretation of the dimensional properties in the object; therefore, to do so would mean to observe the properties that exist in the Yospan dance, both in its music and its dance.

\section{a. The Music}

In interpreting the music to the object, the method used is an experimental method based on the precedent [5] of direct-ear interpretation by visualizing the musical elements into a graph, to which the graph will be projected to the site and translated into architectural form.

The aspects analyzed in the music are: (1) rhytmtempo: the changing tempo and rhythms in the music; (2) density: the amount of noise/musical elements involved; (3) vocal harmony: the dynamics of each vocal element; and (4) feel/emotion: the expression conveyed through the music. This results in four typologies that is then sequenced and projected into the site.

\section{b. The Dance}

The Yospan dance is a simple dance with repetitive movements. It is also flexible, as its moves has many variations with each different performance. The dance formations in Yospan is an aspect that is reminiscence of the Western square dance yet also retains the character of a Papuan dance. As a result, the dance creates three typologies that will be projected into the site.

\section{c. Design Concept}

The design concept as a result of the method consist of zoning and circulation concept, the massing concept, and the spatial sequences concept.

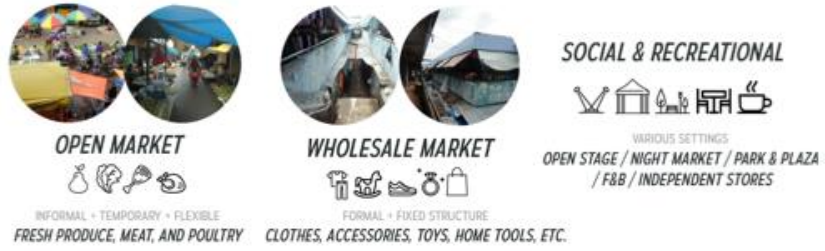

Figure 2. Program

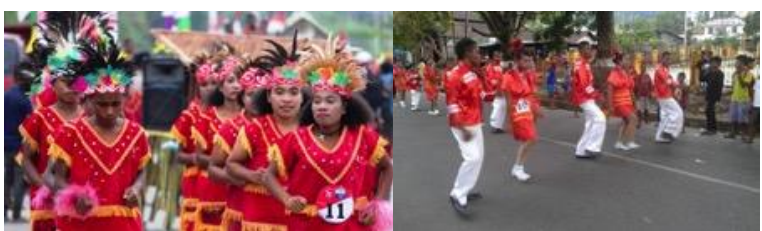

Figure 3. A typical Yospan performance

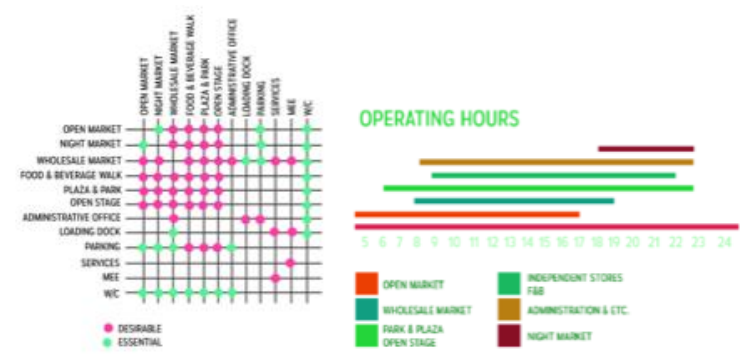

Figure 4. Analysis of programmatic relationships

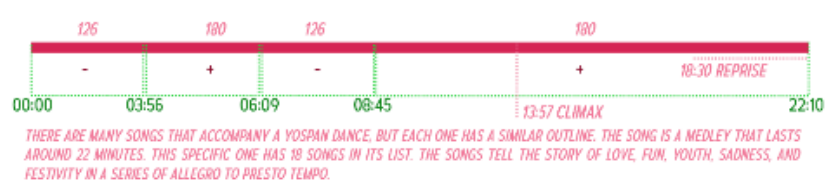

Figure 5. Yospan song structure

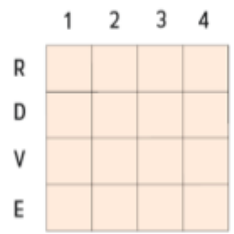

Figure 6. A graph representing a verse in the song

DURATION - 22:10

MEDLEY - 18 SONGS

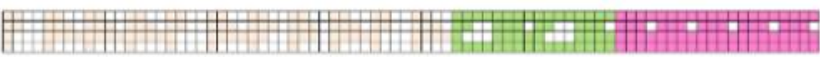

М

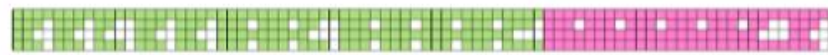

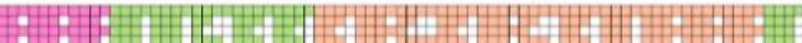

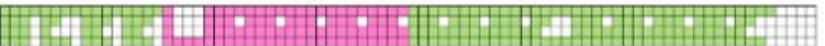

Figure 7. The resulting graph of the whole Yospan song 


\section{Zoning and Circulation Concept}

Using the main linear formation as a means of reaching the open stage at the bay area, the flow is guided by the sequence of the Yospan song. There are approximately six sequences of which each is translated into the corresponding program and is then projected into the site accordingly. The circulation within the site can be divided into three types, of which are circulation of the visitors, vehicles, and materials/produce.

\section{Massing Concept}

The mass is projected from the main dance formations correlating with each programmatic requirement.

- Three circular areas translated as the open market/night market, wholesale market, and F\&B and open stage respectively.

- The linear formation represents the timeline from beginning to end of the song and likewise to the site; starting from the western point and ending at the bay area to the east.

- And the second linear formation represents another part of the wholesale market area that overlaps with the circular formations and respective programs.

\section{Spatial Sequences Concept}

The main sequences were divided into six parts and translated into the site; the resulting zones were then projected with the mass formations, which then results in spatial sequences based on these projections.

a. Sequence 01 - Introduction/Entry

- Correlating program: Parking area and market plaza

- Criteria: Soft materials with complementary finishes, spaced proximity, muted/calming colours, less directed and gives freedom of movement

- Concept: An open plaza, mainly greenery.

b. Sequence 02 - Highlight 01

- Correlating program: Open-air market and night market

- Criteria: Bright, striking colours with hard materials, strong contrasting finishes, intimate proximity and controlled movements through the space

- Concept: Open spaces to accommodate the open market. The stalls are temporary stalls, based on existing open-air market.

c. Sequence 03 - Intermission 01

- Correlating program: Wholesale market, plaza, supporting facilities

- Criteria: Relatively proximate space, hard materials with complementary finishes, relatively controlled movements, between muted and bright colours

- Concept: Programs are in an enclosed building, but with minimum closures in between areas. Plaza functions to connect one program to another.

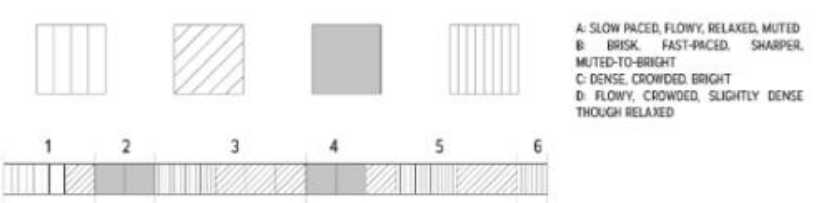

Figure 8. Sequence as a result of the song
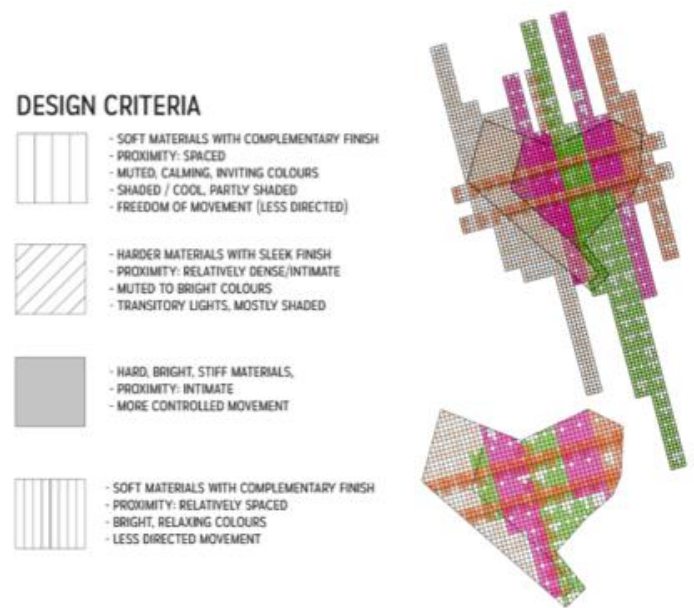

Figure 9. Design criteria as a result of the song (left), projection of the graph/sequence into the site (right)

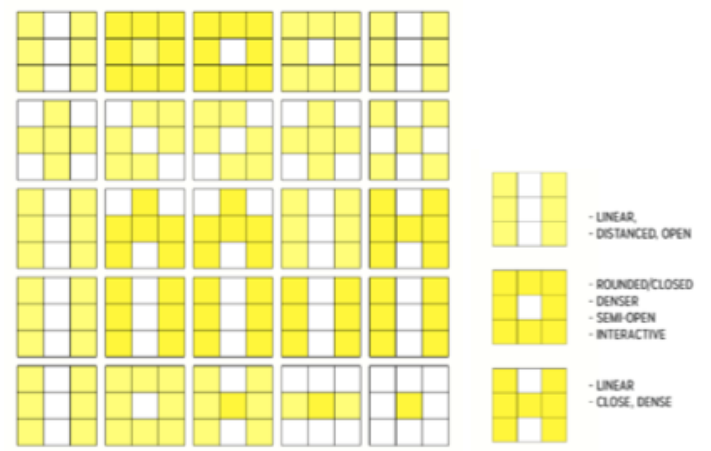

Figure 10. Dance formation graph (left), the three main formations as a result (right)
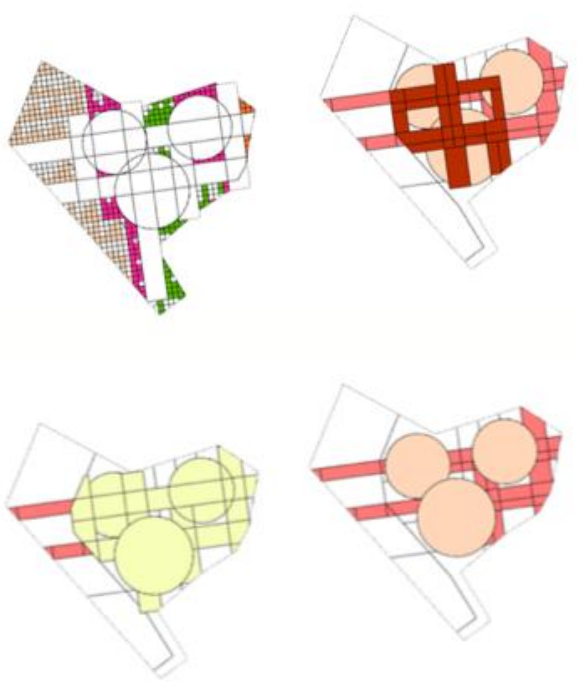

Figure 11. Projection of dance formations to building mass 


\section{d. Sequence $04-$ Highlight 02}

- Correlating program: F\&B area, open stage

- Criteria: Bright, striking colours with hard materials, strong contrasting finishes, intimate proximity and controlled movements through the space

- Concept: An open area surrounded by a semi-enclosed mass

e. Sequence 05 \& 06 - Intermission 02 and Fade out

- Correlating program: Plaza and park

- Criteria: Soft materials with complementary finishes, spaced proximity, muted/calming colours, less directed and gives freedom of movement

- Concept: Recreational paza and park overlooking the bay area, plays with height differences of the ground

\section{DESIGN OUTCOME}

The design process results in two parts, of which are the sequences and the technical exploration.

\section{A. Sequences}

The main site as a result reflects the basic form and sequences of the dance, with the change in materials in each area reflecting the sequence requirements. The colours of the canopies and the façade reflects the image of the previous open market's umbrellas and canopies.

The site starts with an open plaza and ends with an open plaza; with the main programs in between, complementing and contrasting each other. The main sequence is expressed mainly through changes of colour, form, and materials.

\section{B. Technical Exploration}

The main structures use a combination of steel and concrete structures, $60 \mathrm{~cm}$ in diameter. The façade is a system of sun shades with varying sizes of openings, and the top deck functions as an open recreational space covered with canopies of varying heights with a metal frames.

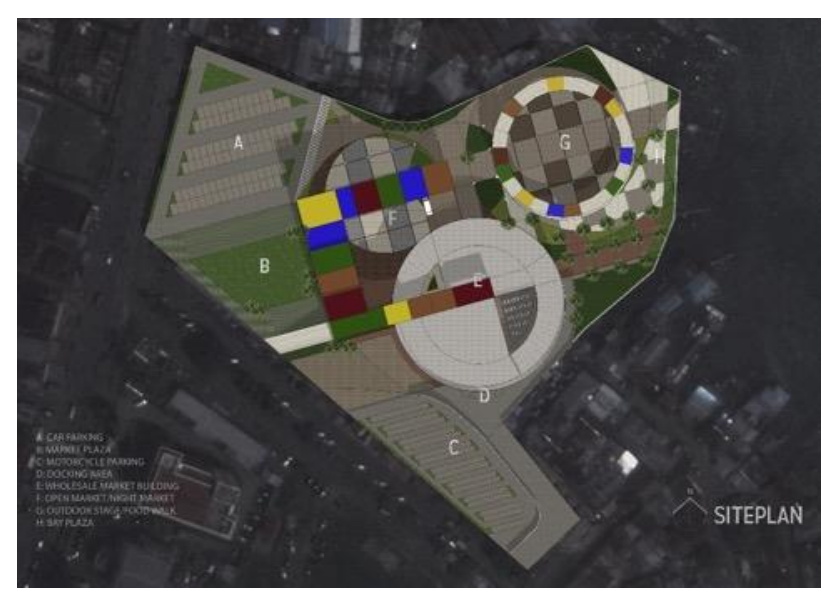

Figure 12. Siteplan

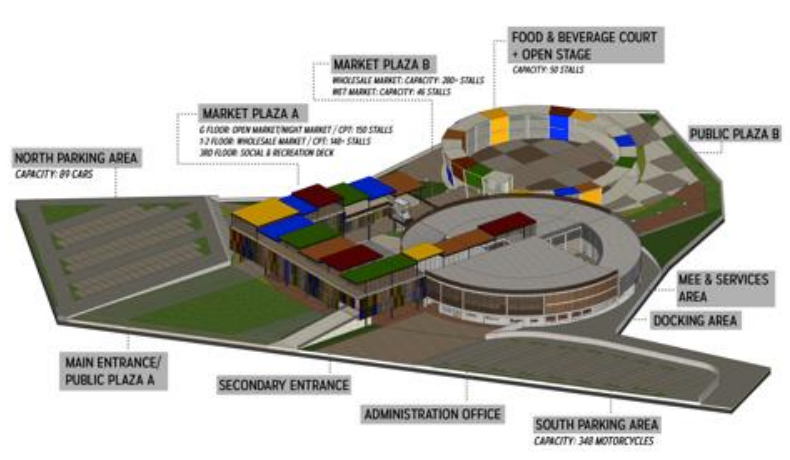

Figure 13. Resulting programs and sequences

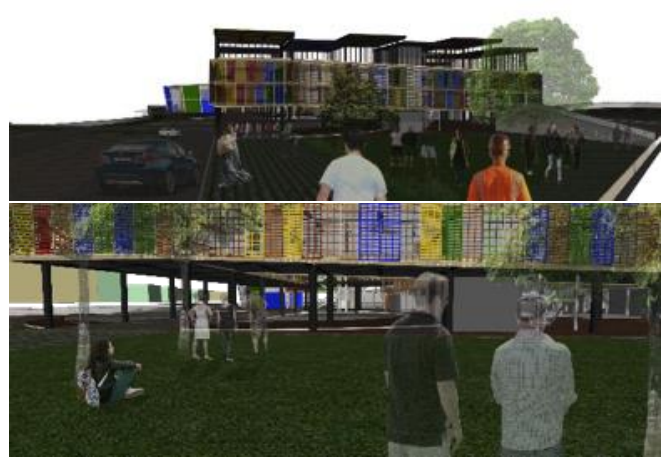

Figure 14. Sequence 01, Entrance and Market Plaza
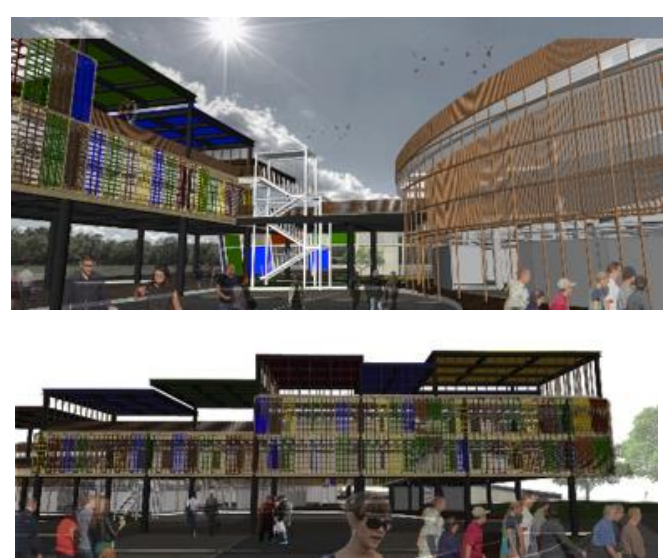

Figure 15. Sequence 02, Open Market

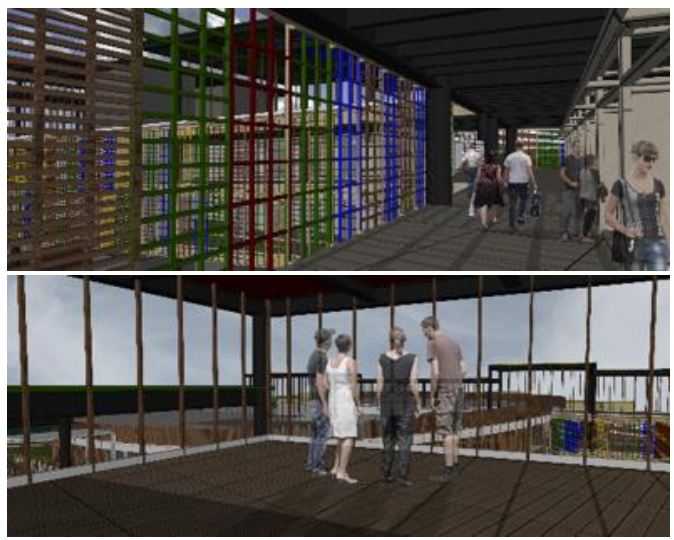

Figure 16. Sequence 02, Building A/Wholesale Market A 


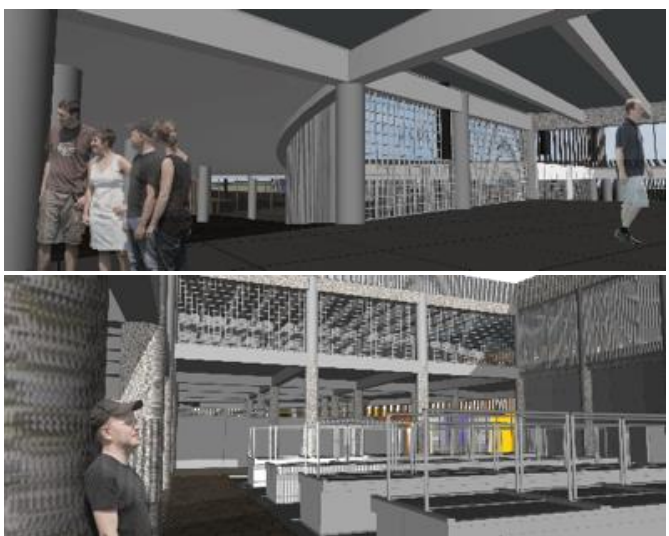

Figure 17. Sequence 03, Building B/Wholesale Market B

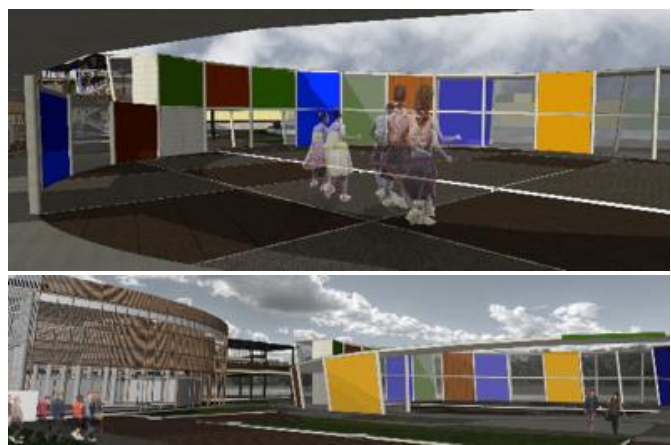

Figure 18. Sequence 04, Open Stage and F\&B Area

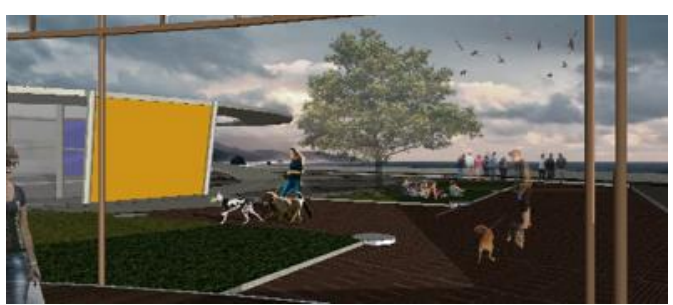

Figure 19. Sequence 05-06, Bay Plaza

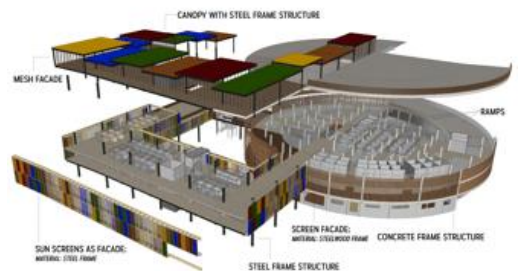

Figure 20. Structure, material, and facade sytem

\section{CONCLUSION}

Through this design, the Sanggeng Market can exist as a marketplace that not only delivers flexible spatial functions but also provide a spatial experience with its various sequences that is exclusive to the character of Manokwari. The Sanggeng market can exist as more than a commercial hub, it can also act as the central social hub of Manokwari, further helping to improve the quality of public spaces in the city.

\section{BIBLIOGRAPHY}

[1] B. Tschumi, Architecture Concepts: Red Is Not A Color. Rizzoli, New York (2012).

[2] A. C. Antoniades, Poetry in Architecture. Van Nostrand Reinhold: New York (1990).

[3] P. Laseau, Graphic Problem Solving for Architects \& Builders. CBI Publishing Company, Boston (1975) 99-101.

[4] Kementerian Pendidikan dan Kebudayaan. (2015, December). Yosim Pancar (Yospan). [Online]. Available: http://kebudayaan.kemdikbud.go.id/ditwdb/2015/12/17/yosim-pancar-yospan/

[5] B. Field. (2009, May). Architecture and Music. [Online]. Available : https://issuu.com/bradenfield/docs/thesis_book 